\title{
Costs of occupational injuries to teenagers, United States
}

\author{
Ted R Miller, Geetha M Waehrer
}

\begin{abstract}
Objectives-This paper estimates the incidence and costs of teenage occupational injuries by severity in the United States. Methods-Existing estimates of occupational injury costs are adapted for the teenage population. Incidence estimates are constructed using data from the US 1993 Annual Survey of Occupational Injury and Illness and the 1993 Census of Fatal Occupational Injuries combined with incidence data from the National Health Interview Survey.

Results-In 1993, an estimated 371000 teenagers were injured in the workplace, accounting for $4.2 \%$ of all occupational injuries. These injuries cost $\$ 5$ billion, approximately $3 \%$ of the total of injury costs involving teenagers.

Conclusions-Teenagers appear to account for a larger share of the total number of occupational injuries relative to their presence in the employed workforce, but a lower share of the costs of such injuries.

(Injury Prevention 1998;4:211-217)
\end{abstract}

Keywords: teenagers; occupational injuries; costs; incidence

Estimates of the incidence and costs associated with occupational injuries provide an objective basis for assessing the need for health and safety measures in the workplace. This paper attempts to obtain these estimates for teenage workers by extrapolating from and combining different sources of information on the costs and incidence of occupational injuries for the general working population. While public attention focuses on exploitative child labor especially in developing countries, this paper highlights the incidence of injuries to teenagers in the United States that occur in legal employment governed by a host of safety regulations. An estimate of the costs of teenage occupational injuries will gauge the importance of this problem and permit cost benefit analyses of measures designed to prevent these injuries.

Approximately $5.3 \%$ of the employed United

National Public Services Research Institute, 8201 Corporate Drive, Suite 220 Landover, $\mathrm{MD}$ 20785, USA

T R Miller

G M Waehrer

Correspondence to: Dr Miller (e-mail: miller@pire.org). example, Parker et al used data on approximately $10 \%$ of students in Minnesota public high schools and estimated that, when injuries are restricted to those resulting in three or more days of lost work or in permanent disability, the occupational injury rate was between $24 \%$ and $40 \%$ for full time employees during 1990-91. ${ }^{3}$ The comparable rate for adults was $10 \%$ in 1988 . Using Washington State Workers' Compensation data, Miller estimated that there were 17800 claims for work related injuries or illness to minors from 1988 to $1991 .^{4}$ The crude injury rates were estimated at $9 \%$ for 16-17 year olds compared with $10.4 \%$ for adults. As teenagers are more likely than adults to be employed part time, however, the injury rate for full time teenage workers could actually be much higher. Schober et al used 24000 occupational injury claims for adolescents reported in the Supplementary Data System of the Bureau of Labor Statistics to estimate an injury rate of $12.6 \%$ for full time male and $6.6 \%$ for full time female employees. ${ }^{5}$ Within the working teenage population, Coleman and Sanderson, using National Electronic Injury Surveillance System (NEISS) data on injuries treated in emergency departments, estimated that 18-19 year old males have the highest rate of occupational injury: $12 \%$ for full time workers compared with a rate of $4 \%$ for all full time workers aged 16 or older. ${ }^{6}$ Castillo et al estimated that 16-17 year olds have a similar rate of fatal occupational injury as those 18 years or older. ${ }^{7}$ The retail industry accounts for approximately half of the teenage occupational injuries, followed by the service sector and agriculture. ${ }^{8}$

In this paper, the accounting framework developed by Miller et $a l^{9}$ is used together with aggregate data on earnings adjusted to reflect a younger population and expenditure figures from Miller and Galbraith ${ }^{10}$ to calculate the costs per teenage occupational injury by severity. Incidence estimates by age group are calculated using data from the 1993 annual Survey of Occupational Injury and Illness (SOII), the 1993 Census of Fatal Occupational Injuries (CFOI), and the National Health Interview Survey (NHIS). The SOII is a representative sample of injuries and illnesses involving work loss. It excludes fatalities at work and work related non-fatal injuries and illnesses to the self employed; to workers on farms with fewer than 11 employees; to private household workers; and to employees in federal, state, and local governments. The CFOI provides a complete count and characteristics of fatal occupational injuries in the United States. The NHIS is a nationally representative household survey that contains data on self reported injuries, their medical treatment, and their resulting work 
losses. Incidence estimates from these sources are combined with costs per injury to give the total costs of teenage occupational injuries.

\section{Methods}

There are few estimates of the cost of occupational injury. Using aggregate data at the national level, Miller and Galbraith estimated that fatal and non-fatal occupational injuries cost society approximately $\$ 140$ billion (1990 dollars) annually. ${ }^{10}$ This estimate includes approximately $\$ 78$ billion dollars in out-ofpocket costs and work loss and lost quality of life valued at $\$ 62$ billion dollars. Using more detailed information at the household level, Marquis calculated the national cost of nonfatal occupational injury to be approximately $\$ 83$ billion, excluding the cost of lost quality of life. ${ }^{11}$

Following Miller et al, ${ }^{9}{ }^{10}$ we discuss different levels of injury severity - fatal injuries and nonfatal injuries. Non-fatal injuries are further divided into injuries with work loss that may or may not be compensable under workers' compensation rules, and injuries without any work loss. We also divide the total costs of occupational injury into three categories: direct costs, indirect costs, and quality of life costs. All costs in this paper are stated in 1993 dollars using the index of medical spending per capita to inflate medical costs, and the employment cost index to inflate all other costs. ${ }^{12}$

\section{DIRECT COSTS OF TEENAGE OCCUPATIONAL}

INJURIES

Direct costs are the out-of-pocket expenses resulting from injury. They include medical and emergency service costs, legal and administrative costs arising from workers' compensation, sick leave and insurance programs, and the cost of workplace disruption as a result of an occupational injury.

Medical and emergency department costs are taken from Miller and Galbraith. ${ }^{10}$ That report assumes that workers' compensation medical payments (including rehabilitation costs) measure medical costs per occupational injury by severity. These costs are assumed not to vary with age.

The percentage of the teenage workforce covered by employer or union provided health plans is treated as a proxy for the percentage who are eligible for benefits like sick leave, health care, and workers' compensation. The average legal and administrative cost per teenage employee is calculated using the per worker costs in table 4 of Miller and Galbraith ${ }^{10}$ and the fact that $52 \%$ of all employees and $24 \%$ of teenage employees were covered by employer or union provided health plans in $1991 .^{1}$

As teenagers' jobs are mostly part time and unskilled in nature, workplace disruption from fatal or compensable teenage injuries is assumed to equal the cost for non-compensable work loss for the average worker. ${ }^{10}$ The cost of workplace disruption for teenage injuries that are non-compensable or involve no work loss is assumed to equal that for a medically treated injury with no work loss reported in Miller et $a .^{13}$

INDIRECT COSTS OF TEENAGE OCCUPATIONAL INJURIES

The indirect costs of an occupational injury value the victim's work loss. They can be approximated by the loss of earnings and fringe benefits as a result of wage work loss associated with injuries, and the loss of household work loss due to the injury.

For fatalities, the lifetime earnings loss is computed using a $2.5 \%$ discount rate (in the range used by courtrooms when deciding injury compensation). The computation methods are adapted from Rice et al, ${ }^{14}$ but use 1991 earnings data that account for unemployment and the sex distribution of teenage work fatalities.

For fatalities, lifetime household work loss is valued using the methods in Rice et $a l^{14}$ and estimated household work losses by age and sex (computed from 1990-91 Census Bureau data on household demographics using the methods outlined in Douglass et $a l^{15}$ ).

For the earnings loss due to non-compensable non-fatal injuries, the median 1991 income of 15-24 year olds (in 1990 dollars) is multiplied by 0.012 (the proportion of median annual earnings for the average worker ${ }^{1}$ that is accounted for by earnings loss due to uncompensated lost work resulting from a non-fatal injury). An analogous calculation is made for household work loss due to an uncompensated non-fatal teenage injury. The proportions used in these calculations are derived from table 4 of Miller and Galbraith. ${ }^{10}$

For non-fatal injuries that result in compensable work loss, probabilities of temporary and permanent disability calculated from Rossman et $a l^{16}$ are combined with wage information and SOII incidence data to estimate that $79 \%$ of the earnings loss is due to permanent disability. To calculate the cost of compensable work loss, $79 \%$ of the lifetime earnings loss for the teenaged worker is multiplied by 0.029 . This is the proportion of lifetime earnings for the average worker accounted for by compensable work loss. It yields the portion of the cost of compensable work loss that may be attributed to permanent disability. Similarly, $21 \%$ of the average annual earnings of the 15-24 age group is multiplied by 0.88 - the proportion of the average annual earnings for the average worker that is accounted for by compensable work loss. This gives the portion of the cost of compensable work loss that may be attributed to temporary disability. The sum of the permanent and temporary components yield the lost earnings per compensable non-fatal teenage injury. Similar calculations estimate the value of lost household work due to injuries with compensable work loss.

QUALITY OF LIFE COST FOR A TEENAGE WORKER The willingness to pay for fatal risk reduction is a comprehensive monetary measure of both the indirect costs and the loss of quality of life resulting from an injury (including the pain 
and suffering costs of the injury victim and the victim's family). In monetizing the intangible losses, willingness to pay estimates differ from cost estimates used in cost effectiveness studies that rely upon non-monetary measures like quality adjusted life years, or in the case of fatality studies, years of potential life lost. Note that we use the willingness to pay of the average worker to calculate the quality of life cost for the teenage worker. We do this in order to avoid underestimating the value of a year of life since teenagers are risk takers and may misperceive the risks associated with a particular enterprise. Also, parents may be willing to pay more for a year of a dependent child's life than a year of their own life. ${ }^{17}$ Finally, we hope our numbers will be used to analyze societal costs and benefits of preventing teenage occupational injuries and therefore, like the Panel on Cost Effectiveness in Health and Medicine, ${ }^{18}$ we favor an egalitarian approach towards valuing a year of life.

The value of the quality of a year of life is assumed to be the same regardless of age. It is calculated as the difference between the estimated willingness to pay for fatal risk reduction and the indirect costs resulting from an occupational injury. The average worker's willingness to pay for fatal risk reduction is measured by estimating the extra wages paid to compensate workers for taking risky jobs. Miller surveyed 30 studies of such compensating wage differentials and computed an average willingness to pay of $\$ 2.7$ million in after tax compensation (in 1993 dollars) per occupational fatality risked or avoided. ${ }^{19}$ (Viscusi suggests higher values between $\$ 3$ and $\$ 5$ million in 1990 dollars. $^{20}$ ) After subtracting the indirect costs from this estimate of the willingness to pay to avoid a workplace fatality, the quality of life cost is approximately $\$ 2.2$ million per fatality for an average worker. Using the ratio of life expectancies of the average and teenage workers, this figure is adjusted to yield a quality of life cost of approximately $\$ 2.6$ million per teenage occupational fatality. In comparing life expectancies, future life years are converted to present value years using a $2.5 \%$ discount rate. Discounting for this purpose is recommended by the Panel on Cost Effectiveness in Health and Medicine ${ }^{18}$ among others.

TOTAL COSTS OF TEENAGE OCCUPATIONAL INJURIES

The total costs associated with the different types of teenage occupational injuries are calculated by multiplying the number of cases of teenage injuries, by severity, times the per injury costs. These calculations are carried out for teenagers 15 years and younger, 16-17, and 18-19. While child labor laws apply only to those under 18 years of age we include 18-19 year olds in our analysis because federal data on youth injuries includes them, and also because employment data for youth is generally available only for the 16-19 age group. In addition, while regulations treat this group differently from other teenagers, they are more likely to be enrolled in school ( $62 \%$ in 1992) than are those 20 years and above, and so may be more similar in their work status to those under 18 years than to the adult population.

The number of teenage injuries involving work loss is calculated by multiplying the 1993 percentage of non-fatal injuries with work loss that are attributable to teenagers in the SOII times 3200000 non-fatal injuries involving work loss in $1993 .^{21}$ The number of fatal occupational injuries is drawn from the CFOI data for 1993.

Several data sources are used to calculate the incidence of non-fatal injuries with no work loss. For the two age groups under 18 years, the number of non-fatal injuries with work loss in the SOII is multiplied by the ratio of NEISS injuries without and with work loss. This ratio is taken from unpublished weighted data on all 14-16 year olds who incurred an occupational injury treated in a NEISS sampled emergency department from July to September 1992. As Knight et al point out, ${ }^{22}$ the exclusion of 17 year olds from the data may bias the percentage of injuries involving work loss downward, because this group may work more hours, are known to have higher injury rates, and work in different industries relative to $14-16$ year olds. On the other hand, the summer months studied may also bias the percentage of injuries with work loss upward, because teenagers work more hours during the summer months and hence, are more likely to incur work loss due to an injury. Finally, reliance on emergency department data that contain relatively more severe cases of injury may skew our estimates in favor of injuries with work loss.

For those aged 18 years and older, the number of non-fatal injuries with work loss in the SOII is inflated using the ratio of 5552000 non-fatal occupational injuries without work loss to 3200000 non-fatal occupational injuries with work loss (National Safety Council ${ }^{23}$ ). Finally, the percentage of injuries without work

Table 1 Costs per teen workplace injury by severity (in 1993 dollars)

\begin{tabular}{|c|c|c|c|c|c|c|}
\hline \multirow[b]{2}{*}{ Cost category } & \multirow[b]{2}{*}{ Fatal injury } & \multicolumn{3}{|c|}{ Non-fatal injury } & \multirow[b]{2}{*}{$\begin{array}{l}\text { All non-fatal } \\
\text { injuries }\end{array}$} & \multirow[b]{2}{*}{ All injuries } \\
\hline & & $\begin{array}{l}\text { Compensated } \\
\text { lost work }\end{array}$ & $\begin{array}{l}\text { Uncompensated } \\
\text { lost work }\end{array}$ & $\begin{array}{l}\text { No lost } \\
\text { work }\end{array}$ & & \\
\hline \multicolumn{7}{|l|}{ Medical and emergency } \\
\hline Legal and administrative & 9100 & 1100 & 25 & 25 & 200 & 200 \\
\hline Work disruption & 1000 & 1000 & 30 & 30 & 200 & 200 \\
\hline Wages/fringe & 1000600 & 24000 & 80 & 0 & 4300 & 4800 \\
\hline Household work & 220500 & 4300 & 60 & 0 & 800 & 900 \\
\hline Subtotal & 1247800 & 38500 & 595 & 455 & 7200 & 7850 \\
\hline Quality of life & 2628000 & 24900 & 0 & 0 & 4400 & 5700 \\
\hline Total cost per injury & 3875800 & 63400 & 595 & 455 & 11600 & 13550 \\
\hline
\end{tabular}


Table 2 Total costs of teen workplace injuries by severity (in 1993 dollars)

\begin{tabular}{|c|c|c|c|c|c|c|}
\hline Injury type & $\begin{array}{l}\text { Total costs per } \\
\text { injury in } \$\end{array}$ & $\begin{array}{l}\text { No of } \\
\text { workplace } \\
\text { injuries }\end{array}$ & $\begin{array}{l}\text { Total cost in } \\
\text { millions of } \$\end{array}$ & $\begin{array}{l}\text { Total cost for all } \\
\text { in millions of } \$\end{array}$ & $\begin{array}{l}\% \text { Of total } \\
\text { workplace injuries }\end{array}$ & $\begin{array}{l}\% \text { Of cost of work } \\
\text { injury for overall } \\
\text { population accounted } \\
\text { for by teens }\end{array}$ \\
\hline Fatal & 3900000 & 168 & 655 & 17600 & 2.7 & 3.7 \\
\hline All non-fatal & 11600 & 371200 & 4306 & 102000 & 4.2 & 4.2 \\
\hline Lost work & 28800 & 146300 & 4213 & 77000 & 4.6 & 5.5 \\
\hline No lost work & 450 & 224900 & 101 & 4053 & 4.1 & 2.5 \\
\hline All types & 13550 & 371400 & 5023 & 128000 & 4.2 & 3.9 \\
\hline
\end{tabular}

Note: the percentages in the last column are calculated using per injury costs in Miller and Galbraith ${ }^{10}$ (inflated to 1993 levels) with 1993 incidence estimates of 6271 fatalities and 8752200 non-fatal injuries (3 200000 with work loss and 5552000 without work loss) from Accident Facts. ${ }^{21}$ These incidence numbers are also used to calculate the percentage of injuries accounted for by teenagers. Incidence numbers may not add up due to rounding.

loss that can be attributed to the three age groups is applied to the estimated 5552000 total non-fatal injuries without work loss to give the total number of teenage occupational injuries without work loss for each age group.

OTHER COMPUTATIONS

In table 1 , the cost per injury over all injuries is calculated as a weighted average of the costs per non-fatal and fatal injury where the weights are derived from the incidence estimates in table 3. Similarly, the cost per non-fatal injury is a weighted average of the cost for injuries with and without work loss. The cost per nonfatal injury with work loss is calculated as a weighted average of the cost of compensable and non-compensable workplace injuries, with the weights derived from the incidence estimates in Miller. ${ }^{24}$

\section{Results}

Table 1 presents the costs per teenage occupational injury by severity. Lost earnings and household work account for approximately $42 \%$ of the total cost per teenage occupational injury compared with $35 \%$ for the total population. ${ }^{10}$ This finding is driven by the fact that the costs of either a fatal injury or a compensable lost work injury are higher for teenagers who have, on average, six more years of productive life than the average worker. In contrast, the cost of short term wage and household work losses for teenagers is approximately half of the $\$ 300$ cost for the average injured worker reported in Miller and Galbraith. ${ }^{10}$

Table 2 presents the estimated total costs of occupational injuries for teenagers and for the total population by severity, and also the percentage of the costs of occupational injuries that can be attributed to teens. The cost of all occupational injuries by severity in table 2 is calculated by multiplying the per injury costs in Miller and Galbraith ${ }^{10}$ (in 1993 dollars) by the incidence estimates for 1993 of 6271 fatalities, 8752000 non-fatal injuries, 3200000 nonfatal injuries with work loss, and 5552000 non-fatal injuries without work loss. ${ }^{21}{ }^{23}$

In table 2, injuries involving lost work account for the bulk of the costs of teenage occupational injury, while injuries involving no lost work are the smallest component. This pattern is similar to that for the general population. ${ }^{10}$ Fatal injuries account for approximately $13 \%$ of the total costs of teenage occupational injury.

Teenage occupational injuries cost $\$ 5$ billion in 1993, approximately $3.9 \%$ of the $\$ 128$ billion cost of all occupational injuries for 1993. This reflects the lower per injury cost of an occupational injury for a teenager relative to the average worker. In terms of incidence, teenagers appear to account for a smaller share of injuries $(4.2 \%)$ relative to the $4.6 \%$ of the

Table 3 Incidence and costs of teen workplace injury in 1993 by severity and age group

\begin{tabular}{|c|c|c|c|c|}
\hline & \multicolumn{4}{|l|}{ Age (years) } \\
\hline & $\leqslant 15$ & $16-17$ & $18-19$ & Total $\leqslant 19$ \\
\hline \multicolumn{5}{|l|}{ Fatal injuries } \\
\hline No & 29 & 38 & 101 & 168 \\
\hline Total fatal cost $(\$)$ & 113100000 & 148200000 & 393900000 & 655200000 \\
\hline \multicolumn{5}{|l|}{ Non-fatal injuries } \\
\hline No with work loss & 1300 & 31700 & 113300 & 146300 \\
\hline No without work loss & 1100 & 26100 & 197700 & 224900 \\
\hline Total No & 2400 & 57800 & 311000 & 371200 \\
\hline Total non-fatal cost $(\$)$ & 27840000 & 670480000 & 3607600000 & 4305920000 \\
\hline \multicolumn{5}{|l|}{ All injury types } \\
\hline No & 2400 & 57800 & 311200 & 371400 \\
\hline Total cost $(\$)$ & 32520000 & 783190000 & 4216760000 & 5032470000 \\
\hline \multicolumn{5}{|l|}{ Monetary } \\
\hline $\begin{array}{l}\text { Medical/emergency medica } \\
\text { services }\end{array}$ & & $101150 \Omega 00$ & 544600000 & 640050000 \\
\hline $\begin{array}{l}\text { services } \\
\text { Legal and administrative }\end{array}$ & $\begin{array}{r}4200000 \\
480000\end{array}$ & $\begin{array}{r}101150000 \\
11560000\end{array}$ & $\begin{array}{r}544600000 \\
62240000\end{array}$ & $\begin{array}{r}649950000 \\
74280000\end{array}$ \\
\hline Workplace disruption & 480000 & 11560000 & 62240000 & 74280000 \\
\hline Wages/fringe & 11520000 & 277440000 & 1493760000 & 1782720000 \\
\hline Household work & 2160000 & 52020000 & 280080000 & 334260000 \\
\hline Quality of life & 13680000 & 329460000 & 1773840000 & 2116980000 \\
\hline
\end{tabular}

Note: from table 1 , cost per injury is $\$ 3900000$ per fatal injury; $\$ 11600$ per non-fatal injury; $\$ 13550$ per injury, all types. No=number. 
employed workforce made up by teenagers aged $16-19$ years. ${ }^{25}$ Note that only $32 \%$ of 16-19 year olds were employed full time in 1993 compared with approximately $85 \%$ of those aged 20 or older. This suggests that, measured in full time equivalents, teenagers may actually account for a disproportionate share of the total number of occupational injuries. Similarly, while teenagers account for $2.7 \%$ of the number of fatal occupational injuries in 1993, the percentage for full time equivalents is probably closer to the percentage of teenagers in the workforce.

The contribution of occupational hazards to the total cost of injuries for teens, and for the general population, can be derived using estimates of total costs from Miller. ${ }^{26}$ Occupational injuries account for less than $3 \%$ of the $\$ 160$ billion (in 1993 dollars) cost of all injuries to $15-19$ year olds in 1991 relative to $8 \%$ of injury costs for the general population.

Table 3 reports the incidence and total costs of teenage occupational injury by severity and age group. In addition, the estimates for the different cost categories are presented. Of the 168 teenage occupational fatalities in 1993, 67 occurred among those less than 18 years of age. There were approximately 370000 non-fatal teenage occupational injuries in 1993, $84 \%$ of which can be attributed to the 18-19 year age group.

Given that teenagers are more likely to work part time, they should be more likely to experience no work loss for a given injury relative to an adult working full time. However, injuries without work loss account for about $61 \%$ of all non-fatal injuries for teenagers relative to $65 \%$ for the general population. This result may be influenced by our use of NEISS data to calculate the incidence of injuries without work loss. As stated earlier, NEISS data are drawn from emergency departments and may therefore be skewed toward more acute injuries that involve work loss.

Recall that teenagers in the 18-19 age group were treated like adults in calculating the incidence of non-fatal injuries without work loss. To check whether this made an appreciable difference to the results, the number of no work loss injuries was recalculated after treating 18-19 year olds like the other teenage groups. The total cost of teenage workplace injuries went down by approximately $\$ 140$ million dollars, a 3\% decrease.

\section{Discussion}

In this paper, we combined a variety of data sources to derive a rough estimate of approximately $\$ 5$ billion dollars for the total cost of teenage occupational injuries. While teenagers account for a slightly smaller share of injuries relative to their presence in the workforce, the probability of a teenage occupational injury may be more or less comparable with that for the average worker once we control for employment in the retail industry where about half of the teenage injuries occur, and for differences in full time status.
These results are troubling since teenagers, particularly those under 16 years of age, are barred from most hazardous employment and hence could be expected to account for a smaller share of the number of occupational injuries relative to their presence in the employed workforce. However, there is considerable heterogeneity in exposure to risk within the teenage population. Since prohibitions on hazardous employment in non-agricultural jobs apply only to those under 18 years old, our incidence estimates may reflect the increased risk that older 18-19 year olds may be legally exposed to in their jobs. Recent data from the 1992-95 CFOI shows that there were 451 occupational fatalities in this age group, 100 of which occurred in the retail industry, followed by the agriculture and construction industries. Also, prohibitions on hazardous agricultural employment cover only those teenagers under 16 years old who are not employed on family farms. For this under 16 group, $71 \%$ of the fatalities in agriculture, forestry, and fishing between 1992-95 occurred while working for the family business. Data from the CFOI also show that from 1992-95, teenagers aged 16-19 years accounted for $15 \%$ of agricultural fatalities, but only $4 \%$ of agricultural employment.

Finally, the relative inexperience of the teenage workforce may make teenagers more likely to suffer injuries relative to more experienced adults. Butani, in a study of the coal mining industry, found that employees with one year or less of experience had a considerably higher than average risk of injury, while those with 15 or more years of experience had a lower than average risk. ${ }^{27}$ This was true for each age group as well as for all age groups combined. Factors like ergonomic misfit between worker size and job, or slippery floors in restaurants where teenagers work in large numbers, may also contribute to the disproportionate share of occupational injuries attributed to teenagers. ${ }^{28}$

Our estimates of the incidence of teenage injuries may be inaccurate if teenage injuries are under-reported in the CFOI and SOII. The CFOI relies on a variety of sources (death certificates, workers' compensation records, Occupational Safety and Health Administration (OSHA) reports etc) for its prevalence based count of occupational fatalities. As Leigh et al report, the CFOI's requirement of two sources to confirm a death may lead to an undercount because employers may not be willing to list occupational deaths for fear of OSHA investigations. $^{29}$ Furthermore, a significant proportion of occupational deaths are motor vehicle related (leading to an undercount of occupational injuries if the coroner or police are not aware that the victim was "at work"). Both these problems may be greater for teenage workers than for the general population.

To check the validity of the CFOI incidence estimates we compared them with other estimates in the literature. The CFOI reports 67 occupational fatalities for children under 18 years: approximately $1.1 \%$ of a total of 6271 for all age groups in 1993. Suruda and Halperin analyzed OSHA fatality investigations and 
reported that the under 18 age group accounts for $1.3 \%$ of the 8000 work related deaths that they estimate occur every year. ${ }^{30}$ Finally, data from the National Traumatic Occupational Fatalities (NTOF) surveillance system give a percentage of approximately $1.1 \%$ for $16-17$ year olds for the years 1980-89 (Castillo et $a l^{7}$ ). The corresponding percentages for this age group from CFOI and Suruda and Halperin ${ }^{30}$ are $0.6 \%$ (38 deaths) and $1.1 \%$ (90 deaths), respectively. If the Suruda and Halperin estimate of $1.3 \%$ for the under 18 age group were applied to the CFOI estimate of 6271 occupational fatalities in 1993, the total cost of teenage occupational fatalities would be approximately $\$ 712$ million as opposed to $\$ 655$ million using CFOI estimates - approximately $9 \%$ higher. The total costs of teenage occupational injury would increase by only $1.2 \%$.

The NTOF data and, in large part, the CFOI rely on death certificates to identify fatalities. Stout and Bell report that, on average, death certificates account for only $81 \%$ of work related deaths. ${ }^{31}$ Runyan et al document the bias in medical examiners' certification of work injuries especially for the young and for those who work at home. ${ }^{32}$ Injuries to teenagers working on family farms may also be less likely to be classified as work related. Thus, the estimates of the total costs of teenage occupational fatalities presented here must be considered conservative.

The SOII may also suffer from underreporting of non-fatal injuries. As Leigh et al point out, OSHA enforcement has indirectly relied on SOII data, giving employers an incentive to cover up injuries. ${ }^{29}$ This undercounting may be more pronounced for nonfatal injuries which are easier to conceal than deaths in the workplace. Also, the survey excludes government employees, self employed persons, private household workers, and farms with fewer than 11 workers from its count of non-fatal injury victims. Thus, children who are injured while working for their parents or in the other areas excluded from the SOII may not be adequately represented in the injury count. Furthermore, as teenagers are more likely to work part time, injuries involving work loss are less likely to be counted for the teenage population relative to the general population.

In order to gauge if the SOII data yield too low an estimate of teenage occupational injury, they are compared with estimates by Layne et al from NEISS. ${ }^{8}$ This system provides data on non-fatal occupational injuries treated in a sample of representative emergency departments across the United States. An estimated 64100 cases of occupational injury to teenagers under 18 were treated in emergency departments in 1992. Approximately $55 \%$ of these cases involved lost workdays yielding an estimate of roughly 35300 teenagers under 18 with occupational injuries involving lost work in 1992 . This is $71 \%$ higher than the SOII estimate of 20700 lost workday cases in 1993 for teenagers under 18 years, thus providing further evidence that the SOII undercounts lost workday injuries for teens. The NEISS data themselves may result in an undercount since studies suggest that only $36 \%$ of work related injuries are treated in emergency departments. $^{6}$ Given the disparity between NEISS estimates and incidence figures from the SOII, the total costs of occupational injuries for the under 18 age group may well be higher than the level reported here.

On the other hand, our per injury cost estimates are largely derived from figures for the average worker and hence, may overstate the true cost per teenage injury. Specifically, cost per lost workday injury is an average of compensable and non-compensable injury costs weighted by the relative incidence of such injuries for the general working population. Since the duration of work loss is longer for older segments of the population relative to teens, the weight on compensable injuries in the general population is likely to be larger than for the teenage population, resulting in an upward bias in our costs per lost workday injury. Our use of NEISS emergency department data may also result in an overstatement of the costs per injury since they are likely to be biased toward injuries involving work loss.

Since medical costs are derived from workers' compensation claims that are more likely to be filed by adults with longer durations of work loss, our estimates of medical costs per teenage injury may be overstated. The use of workers' compensation data to estimate medical costs also assumes that the level of medical costs does not vary with coverage under workers' compensation. This assumption may not be valid. Since medical costs are fully covered under the program there is no incentive for doctors to provide the most cost efficient service.

\section{Conclusion}

Teenage injuries account for a larger share of occupational injuries than would be expected under the current regulations governing child labor in the United States. The exposure to hazardous employment particularly among 18-19 year olds as well as lack of experience in teenage workers relative to adults may contribute to this phenomenon. Lost earnings and household work account for a larger percentage of the cost of teenage occupational injuries than other occupational injuries. While this paper has focused on the experience of teenage workers in the United States, it is relevant in other countries like Canada and the United Kingdom where approximately $49 \%$ and $61 \%$ respectively, of male teenagers aged $15-19$ participated in the labor force in $1995 .{ }^{33}$ Other developed countries with documented high rates of labor force participation include Australia, Denmark, and Germany.

Increasingly, the focus on occupational safety has expanded to teenage workers. In the United States, the National Occupational Research Agenda identifies increased study of special populations like adolescents as one of its priorities. More attention is needed to improve the data on the incidence of teenage occupational injuries, particularly with respect to different levels of severity. Better data on the employment status of teenagers are also 
needed, especially for those under 16 years of age. The figures reported in this paper are approximate, based as they are on macrolevel estimates of expenditures and earnings. Estimates using detailed microlevel data would more accurately portray the costs of teenage occupational injuries.

This project was supported by grant R01 OH12179 from the National Institute for Occupational Safety and Health of the Centers for Disease Control and Prevention.

1 Bureau of the Census. US statistical abstract, 1993. Washington, DC: US Government Printing Office, 1993.

2 Brooks D, Davis L, Gallagher S. Work-related injuries among Massachusetts children: a study based on emeramong Massachusetts children: a study based on emer-

3 Parker D, Carl W, French L, et al. Nature and incidence of self-reported adolescent work injury in Minnesota. $A m \mathcal{F}$ Ind Med 1994;26:529-41.

4 Miller M. Occupational injuries among adolescents in Washington state, 1988-1991: a review of workers' compensation data. Technical report 35-1-1995, Olympia, WA: Safety and Health Assessment and Research for Prevention, Washington State Department of Labor and Industries, 1995.

5 Schober S, Handke J, Halperin W, et al. Work-related injuries to minors. Am 7 Ind Med 1988;14:585-95.

6 Coleman P, Sanderson L. Surveillance of occupational injuries treated in hospital emergency rooms-United States, 1982. MMWR Morb Mortal Wkly Rep 1983;32:31SS-7.

7 Castillo D, Landen D, Layne L. Occupational injury deaths of 16- and 17-year olds in the United States. Am f Public Health 1994;84:646-9.

8 Layne L, Castillo D, Stout N, et al. Adolescent occupational injuries requiring hospital emergency department injuries requiring hospital emergency department treatment: a nationally repre

9 Miller T, Calhoun C, Arthur WB. Utility-adjusted impairment years: a low cost approach to morbidity valuation. Estimating and valuing morbidity in a policy context: proceedings of a fune 1989 association of environmental and resource economists workshop. Washington, DC: US Environmental Protection Agency, 1989.

10 Miller T, Galbraith M. Estimating the costs of occupational injury in the United States. Accid Anal Prev 1995;27:741-7.

1 Marquis MS. Economic consequences of work-related injuries. Santa Monica, CA: RAND, 1992.

12 Clinton WJ. Economic report of the president. Washington, DC: US Government Printing Office, 1997.

13 Miller T, Lawrence B, Jensen A, et al. Estimating the cost to society of consumer product injuries: the revised injury cost model. Bethesda, MD: US Consumer Product Safety Commission, 1998.
14 Rice D, MacKenzie E, Associates. Cost of injury in the United States: a report to congress. San Francisco: Institute for Health and Aging, University of California, and Injury Prevention Centre, Johns Hopkins University, 1989.

15 Douglass J, Kenney G, Miller T. Which estimates of household production are best? F Forensic Econ 1990;4:25-46.

16 Rossman SB, Miller T, Douglass JB. The costs of occupational musculoskeletal and severe occupational traumatic injuries. Final report to NIOSH. Washington, DC: Urban Institute, 1991.

17 Blomquist G, Miller T, Levy DT. Values of risk reduction implied by motorist use of protection equipment: new evidence from different populations. Fournal of Transport Economics and Policy 1996;30:55-66.

18 Gold M, Siegel J, Russell L, et al, eds. Cost-effectiveness in health and medicine. New York: Oxford University Press, 1996.

19 Miller T. The plausible range for the value of life: red herrings among the mackerel. F Forensic Econ 1990;3:17-

20 Viscusi WK. The value of risks to life and health. Fournal of Economic Literature 1993;31:1912-46.

21 National Safety Council. Accident facts, 1994 edition. Itaska, IL: National Safety Council, 1994.

22 Knight E, Castillo D, Layne L. A detailed analysis of workrelated injury among youth treated in emergency departments. Am f Ind Med 1995;27:793-805.

23 National Safety Council. Accident facts, 1995 edition. Itaska, IL: National Safety Council, 1995.

24 Miller T. Injuries to workers and their dependents. F Safety Res 1994;26:75-86.

25 Bureau of the Census. US statistical abstract, 1994. Washington, DC: US Government Printing Office, 1994

26 Miller T. Costs of injuries in 1991 by cause, United States. Working paper. Landover MD: National Public Services Research Institute, 1995.

27 Butani S. Relative risk analysis of injuries in coal mining by age and experience at present company. Fournal of Occupational Accidents 1988:10:209-16.

28 Hayes-Lundy C, Ward RS, Saffle JR, et al. Grease burns at fast food restaurants: adolescents at risk. $\mathcal{F}$ Burn Care Rehabil 1991;12:203-8.

29 Leigh JP, Markowitz S, Fahs M, et al. Costs of occupational injuries and illnesses. Final report U60/CCU90288. Cincinnati: NIOSH, 1995.

30 Suruda A, Halperin W. Work-related deaths in children. $\mathrm{Am}$ f Ind Med 1991;19:739-45.

31 Stout N, Bell C. Effectiveness of source documents for identifying fatal occupational injuries: a synthesis of studies. Am F Public Health 1991;81:725-8.

32 Runyan CW, Loomis D, Butts J. Practices of county medical examiners in classifying deaths as on the job. Fournal of Occupational Medicine 1994;36:36-41.

33 Organization for Economic Cooperation and Development. Labour force statistics, 1974-1994. Paris: OECD, 1996. 